Palimpsesto Vol. 10, $\mathrm{N}^{\mathrm{o}} 17$ (enero-junio, 2020): 120-134

Universidad de Santiago de Chile, ISSN 0718-5898

Montserrat Amores

Universidad Autónoma de Barcelona

montserrat.amores@uab.cat

\title{
La historia de la literatura de México y la literatura española en $E l$ Museo Mexicano (1843-1846) ${ }^{*}$
}

\section{The History of Mexican Literature and Spanish Literature in $E l$ Museo Mexicano (1843-1846)}

\begin{abstract}
Resumen
En uno de los periodos clave en la conformación de la nación mexicana, El Museo Mexicano (1843-1846) se presenta como un medio idóneo para contribuir a su construcción. En la revista los textos literarios y los dedicados a la historia y a la crítica literarias mexicanas muestran un continuo diálogo con la literatura española que se descubre como un referente problemático. El artículo estudia, por un lado, el lugar que ocupa la literatura española en la revista mexicana teniendo en cuenta su importancia para el establecimiento de la periodización de la historia de la literatura y del canon, a través del análisis de un artículo de Guillermo Prieto; por otro, la presencia de escritores españoles coetáneos que se proponen como modelo en la revista y las redes establecidas con la publicación madrileña El Laberinto en la segunda época del semanario mexicano.
\end{abstract}

Palabras claves: Historia de la literatura mexicana, Literatura española, El Museo Mexicano, redes transatlánticas, Prensa mexicana del Siglo XIX.

\begin{abstract}
In one of the most important periods of conformation of the Mexican nation, El Museo Mexicano (18431846 ) is presented as an ideal medium to contribute to its construction. In the magazine, literary texts and those dedicated to Mexican history and literary criticism are presented in continuous dialogue with Spanish literature as a problematic reference. The article studies, on the one hand, the place that Spanish literature occupies in the Mexican magazine, taking into account its importance for the establishment of the periodization of the history of literature and the canon through the analysis of an article by Guillermo Prieto; on the other hand, the presence of contemporary Spanish writers who are presented as a model in the magazine and the networks established with the Madrid magazine, El Laberinto, in 1845-1846.
\end{abstract}

* Este artículo de investigación ha sido posible gracias a la ayuda del proyecto PGC2018-095312-B-I00

"Negociaciones identitarias transatlánticas: España-Francia-México (1843-1863)". 
Keywords: History of Mexican literature, Spanish Literature, El Museo Mexicano, Transatlantic networks, 19th century Mexican press.

\section{Introducción}

La hemerografía constituye una disciplina auxiliar imprescindible de la historia literaria, no solo porque la prensa periódica se establece como una de las principales difusoras de textos de creación y de crítica literaria, sino también porque es un medio idóneo para la circulación y discusión de principios estéticos que articulan la periodización de la historia de la literatura. Ese clima de opinión que propician sobre todo las revistas literarias en el siglo XIX es fundamentalmente fértil en la construcción de imaginarios nacionales $y$, en especial, problemático en el contexto de las complejas relaciones entre España y México, señaladas desde los estudios de la historia de las mentalidades. Así, para Tomás Pérez Vejo "la trilogía romántica de nación, raza y lengua y cultura era en las nuevas repúblicas prácticamente indistinguible de la que la antigua metrópoli enarbolaba como propia" (2010, p.223). El historiador español advierte que, en el caso mexicano, como en el resto de los países de Latinoamérica, "el otro es, en sentido literal, uno mismo" (2010, p.223), de forma que la nación mexicana intenta construirse rechazando parte de la historia común compartida con España, sin poder sustraerse de una misma lengua y cultura. "Hispanofobia e hispanofilia se convierten en dos corrientes paralelas que recorren la vida mexicana desde la Independencia y afloran con especial virulencia en momentos de crisis política" (Suárez Cortina y Pérez Vejo, 2010, p.28).

Como revista ilustrada con vocación nacionalizadora, El Museo Mexicano, o Miscelánea Pintoresca de Amenidades Curiosas e Instructivas se erige como un medio idóneo para contribuir a la construcción de la nación y, por ende, de su literatura, teniendo en cuenta que en ese proceso, como ha estudiado François-Xavier Guerra, la nación se articula a través de dos ejes: el que remite al pasado, a la historia, y el que mira hacia el futuro como un proyecto en el que convergen los habitantes de un país (Guerra, 1992, p.317).

La revista se publicó semanalmente desde marzo de 1843 hasta marzo de 1846 en la imprenta de Ignacio Cumplido y se presenta como continuación de El Mosaico Mexicano (18361842). En su breve historia de la revista Magdalena Alonso Sánchez ha distinguido dos épocas "de desigual fortuna". La primera abarcaría los cuatro primeros tomos que comprenden los años 1843 y 1844 bajo la dirección de Guillermo Prieto y Manuel Payno, mientras que la "Segunda época", así consta en la portada del tomo y con José María Lacunza a la cabeza, compendia los años 1845 hasta marzo de 1846 (Alonso Sánchez, 2001, p.558; también Castro y Curiel, 2010, p.277) con el título Museo Mexicano. El semanario sigue las directrices de las publicaciones pintorescas y se distingue por su carácter enciclopédico y misceláneo. Alonso Sánchez ha destacado algunos de sus rasgos esenciales: "la originalidad de sus artículos, la presentación exclusiva de autores nacionales y la conformación plural de un grupo de colaboradores" (2001, p.555). No obstante, estos rasgos deben matizarse, puesto que un número considerable de artículos publicados en la revista no fueron originales. El Museo Mexicano se nutrió, quizá no tanto como otras revistas mexicanas de la época, de traducciones de textos franceses e ingleses y de algunos textos españoles. Por otra parte, aunque publicó documentos de la Academia de Bellas Artes de Puebla, de la Academia Literaria de Morelia y de otras instituciones creadas 
recientemente en el país (Alonso Sánchez, 2001, p.557), el grueso más importante de los colaboradores proviene de la Academia de Letrán, razón por la cual Pérez Benavides (2005) y Vega y Ortega Báez (2014) defienden que El Museo Mexicano fue el órgano literario de esta Academia.

En el caso de la articulación del sistema literario mexicano, puede afirmarse que sigue los mismos patrones que los analizados en lo referente a la construcción de la nación delimitados por Suárez Cortina y Pérez Vejo:

Por lo que respecta a la construcción de la nación, México es la contraparte casi perfecta de España. Mientras ésta se autoerige en continuadora y heredera de la antigua Monarquía, aquél lleva más lejos que ninguna de las otras naciones americanas la imagen de una nación prehispánica, muerta con la Conquista y resucitada con la Independencia, la copia en negativo de la nación imaginada por España. La una heredera de los conquistadores y de la tradición imperial; la otra de los conquistados y de la venganza de la independencia. (Suárez Cortina y Pérez Vejo, 2010, p.16)

Estos principios pueden aplicarse igualmente a la construcción de la historia de la literatura mexicana. Como se verá, en El Museo Mexicano la literatura española se encuentra en los textos relacionados con esta disciplina como un referente problemático, pues la conquista destruye la nación prehispánica, aunque la producción literaria mexicana se mira en el espejo de la tradición española para perfilar la periodización y cimentar un canon. Asimismo, construye la literatura del presente y la del futuro contando con la obra de autores españoles coetáneos, cuyos textos se encuentran en las páginas de la revista.

\section{Los “desordenados apuntes" de literatura mexicana de Guillermo Prieto}

El artículo más importante relacionado con esta disciplina pertenece a uno de los directores de la primera etapa. Se trata de "Algunos desordenados apuntes que pueden considerarse cuando se escriba la historia de la bella literatura mexicana" de Guillermo Prieto, que vio la luz en el tomo de 1844. El texto debe enmarcarse en las reuniones semanales de los miembros del Ateneo, pues algunas de las ideas desarrolladas por Prieto en este artículo coinciden o se complementan con las expuestas por otros miembros de esta asociación, como José María Lafragua o Luis de la Rosa, que se publicaron en El Ateneo Mexicano. Con una mirada dirigida tanto al pasado como al futuro, la revista de este órgano cultural pretendía crear "un establecimiento que no solamente fuera conservador de las luces, sino el manantial de donde se difundiese éstas", como recuerda Francisco Ortega en su artículo "El porvenir de la literatura" editado en esa misma publicación (cit. en Ruedas de la Serna, 1996, p.128).

"Algunos desordenados apuntes" contribuye al fortalecimiento de la conciencia nacional al conjugar la identificación de aquellos aspectos estéticos de los textos literarios con los relativos a la importancia del compromiso social del escritor. Por otra parte, considerando la disciplina de la historia de la literatura, Prieto mira hacia el pasado para establecer una secuenciación de la literatura mexicana en la que lo nacional, entendido como "representativo del carácter de un pueblo", será el principio sustentador que determina la selección de los escritores que aparecen en esos "apuntes", que debe considerarse como una propuesta de canon. De hecho, el texto se inicia 
con la noticia de la publicación del volumen Obras poéticas de Fernando Calderón, editado por Ignacio Cumplido y precedido de un prólogo de Manuel Payno, y el anuncio de la colección de poesías planeada por el impresor, que no llegó a publicarse (Ruiz Castañeda, 2014, p.55). En esas primeras líneas indica que su propósito es el de "consignar en este artículo algunos nombres que, como el de D. Fernando Calderón, son acreedores a la gratitud pública" (G.P., 1844, p.354). A su vez, deteniéndose en la literatura del presente, anunciará un programa de política cultural mexicana.

Prieto parte de la distinción de las dos amplias etapas que para la historia literaria había distinguido ya en 1755 la Biblioteca mexicana de Eguiara y Eguren: la anterior a la conquista y la colonial. Para la primera, de la que solo cita entre paréntesis los Cantos de Netzahalcoyolt, considera la importancia de los aztecas como la etnia mítica, que es el verdadero sujeto de la nación, aunque se trata de una etnia ahogada durante la conquista, sobre la que se impuso una nueva civilización. Para argumentar el razonamiento cita a Xavier Marmier ${ }^{1}$, que señala que en los orígenes de toda poesía "aparece el poeta lírico, el cantor de las primeras glorias" (G.P., 1844, p.355), mostrando la diferencia existente entre la literatura de las sociedades nacientes y la primitiva sociedad mexicana:

La sociedad primitiva, esto es (la Azteca) con la poesía de sus recuerdos y de sus glorias, se perdía de súbito en el torrente de la raza invasora [...] la nuestra fue en su origen una sociedad trasplantada, que importaba a nuestro suelo su fe, y sus costumbres, su idioma y sus recuerdos. Faltaba al canto del bardo, espontaneidad, independencia; no había inspiración, era eco de otra sociedad gastada, que con sus orgullosos mandatarios nos enviaba de real orden un sistema de pensar y de sentir. (G.P., 1844, p.355)

Prieto coincide con las ideas de José María Lacunza defendidas también en las páginas de El Museo Mexicano, para quien las civilizaciones anteriores a la conquista habían desaparecido y no era posible encontrar los orígenes de la nación mexicana en el período prehispánico: "murió el cuerpo social con sus costumbres y con sus leyes, con sus religiones, y aún con sus dioses" (Lacunza, 1844, p.364; véase Pérez, 2005, pp.47-50). Igualmente, resuenan las palabras de Luis de la Rosa en la conferencia leída en una sesión dominical del Ateneo de abril de 1844, titulada "Utilidad de la literatura en México" en la que, con un tono más severo que Prieto y Lacunza, sentencia: "En donde no hay patria, señores, no hay poesía; en donde unos cuantos mandan como tiranos orgullosos, y todos los demás tiemblan a la voz de su señor, como esclavos envilecidos; en donde no hay, en fin, toda la libertad que es compatible con el orden [...]" (Rosa, 1996, p.99). ${ }^{2}$

A partir de ese momento, en esos apuntes para la historia de la literatura mexicana las producciones literarias de la nación se estiman siempre en relación con la literatura española: al esplendor de la literatura de la metrópolis le corresponde la decadencia de las letras mexicanas, "porque nuestra sociedad no era sino una fracción degradada de la de los descendientes de Pelayo" (G.P., 1844, p.354).

\footnotetext{
${ }^{1}$ Manuel Payno había traducido algunos poemas de los Chants populaires du Nord de Marmier para El Museo Mexicano (M.P., 1843: 202-204).

${ }^{2}$ Se publicó en El Ateneo Mexicano, I (1844), pp. 205-211 y en julio de ese mismo año en El Siglo Diez y Nueve (véase Díaz Arciniega, 1996: 82, n. 4). Años después también el poeta español José Zorrilla sentenciará en La flor de los recuerdos (1855) que la literatura de México "fue solo un reflejo de la española mientras México fue español” (cit. en Martínez, 1955: 43).
} 
También la influencia de la literatura española siguió marcando la decadencia de la literatura mexicana tras el periodo de colonización, correspondiente a una época en la que no se cultivó la literatura, en sentido moderno, en México, y que coincidió con el Siglo de Oro de la española. Sin embargo, para el polígrafo mexicano, cuando

comenzó para México la existencia intelectual, fue casualmente en la época de corrupción y decadencia de la buena literatura española, en ese siglo XVII en que la puerilidad y la hinchazón desnaturalizaban la realidad del sentimiento, y en que el culteranismo ridículo contagiaba los ingenios más aventajados de la monarquía (G.P., 1844, p.355)

De entre los escritores mexicanos del siglo XVII Prieto destaca a Eusebio Vela, a Juan Ruiz de Alarcón, aunque, según su opinión, el segundo debe considerarse español, a Juan José de Arriola, y su comedia No hay mayor mal que los celos, y a Juan Muñoz Molina. También se refiere a sor Juana Inés de la Cruz, aunque su veredicto no sea satisfactorio, pues, "sus poesías pertenecen desgraciadamente a la mala época a que dio su nombre Góngora" (p.356). En esencia, Prieto tiene como referente para la literatura el sistema racional dieciochesco, razón por la cual, rechaza a Góngora y a Sor Juana, destacando cómo la poesía neoclásica restituye a los poetas españoles renacentistas.

El balance de la poesía mexicana de los siglos XVII y XVIII no puede ser más negativo: "Poesías fugitivas, copias pueriles de la pueril poesía española del siglo XVII; rimas insustanciales a natalicios y festividades de santos, y tal cual composición satírica; he aquí nuestra humilde literatura" (p.355). En el siglo XVIII que "fue para México el siglo de oro de las ciencias y de las artes" (p.356), a diferencia del panorama español, en la poesía mexicana solo se encuentra la traducción de la Ilíada del padre Alegre y la de Virgilio de José Rafael Larrañaga.

No será hasta mediado el siglo XVIII cuando florezcan en España los "nobles ingenios" de Luzán, Iriarte, Moratín y Meléndez Valdés. ${ }^{3}$ Sin embargo, nada de ese "buen gusto" se cultivó en México, donde no llegó la Poética de Luzán, y la poesía se basaba únicamente en "serviles imitaciones de la corrompida literatura española" (p.357). En realidad, Prieto defiende la necesidad de seguir una preceptiva que destierre el gongorismo y el descuido prosódico en la poesía de su país. Además, ese estado deplorable de la literatura mexicana se debía, según el autor, al concepto poco decoroso que se tenía entonces de la poesía, vista solamente "como un desahogo de las ocupaciones serias" (p.356), y a la escasa preocupación de las instituciones por los estudios humanísticos.

Ya en los primeros años del siglo XIX menciona a "Barquera, Lacunza, Barazabal, Azcárate, Bustamente", y, sobre todo a Lizardi y su Periquillo Sarniento, y a Gorostiza, aunque, como Alarcón, pertenece a la literatura española. En la poesía festiva señala al padre Anastasio Ochoa y a Francisco Ortega.

Tampoco la Independencia, "la libertad, el heroísmo, la lucha gloriosa de que salía la nación triunfante" (p.358), llevó a México la resurrección de las letras. Prieto identifica el año 1821 con la "cuna de la sociedad naciente", con el momento propicio para buscar en él una floreciente literatura nacional:

${ }^{3}$ El Museo Mexicano publicó en 1845 un "Juicio crítico" de las obras del ilustrado español que había publicado dos años antes El Laberinto (Alcalá Galiano, 1843 y 1845). 
Entonces la inspiración debió haber descendido a la lira del poeta, y éste, en la hora solemne de la resurrección de un pueblo, identificándose con él en sentimiento, desplegando su voz augusta, circuido de los héroes, elevado sobre sus conciudadanos libres, debió invocar los más sublimes sentimientos de religión y de amor, para saludar la aurora de la existencia de su patria. (G.P., 1844, p.358)

El autor se refiere con estas palabras al poeta de evocaciones mesiánicas, capaz de revivir el proceso revolucionario con la grandeza de las hazañas del heroico pueblo, un proceso que no llegó a producirse tampoco en esta ocasión en México con el esplendor esperado. Para el polígrafo, a pesar de que "las agitaciones políticas levantaron en un oleaje un trono, a los que a él se acercaban se tornaban pigmeos y sin prestigio" (p.358) y muy pronto llegó la decepción para los hombres de letras. Tampoco en estas circunstancias México pudo desarrollar una verdadera literatura nacional porque "para que una literatura adquiera un tipo especial, es forzoso que las producciones de los otros países se modifiquen, se aclimaten, y por una sucesión de trabajo, se transformen y conviertan en literatura característica de un pueblo" (p.358) y la revolución no se resolvió con respuestas propias del país, sino siguiendo modelos estadounidenses o españoles.

El diagnóstico de Prieto es semejante al que había realizado poco antes José María Lafragua en el discurso que sirvió de sesión inaugural del Ateneo Mexicano en ese mismo año, titulado "Carácter y objeto de la literatura", publicado en la revista El Ateneo Mexicano, en el que resuenan las ideas del "Prefacio al Cromwell" de Victor Hugo, como ha señalado Blanca Estela Treviño (en Ruedas de la Serna, 1996, p.65).

Así, nuestra literatura hasta 1821, con muy honrosas excepciones, estuvo reducida a sermones y alegatos, versos de poco interés, descripciones de fiestas reales y honras fúnebres, y alguna letrilla erótica. Ni podía ser de otra manera, cuando la sociedad no tenía carácter propio. Vino la Independencia; y durante tres lustros, la patria, el gobierno, la libertad ocuparon exclusivamente nuestros ánimos. Y aunque este campo era vasto, la literatura no podía fecundarlo, porque la política tenía en continua acción todos los resortes sociales: la expresión de nuestra sociedad eran nomás los periódicos... (Lafragua, 1996, p.75)

Ambos coinciden en la periodización fundamental de la época (Tola de Habich, 2005, p.203). Como se ha indicado anteriormente, la intrínseca relación entre sociedad y literatura que establece Prieto explica el proceso. En estas circunstancias, la prensa periódica jugó un papel consustancial: si bien la libre circulación de libros dio a conocer a otros escritores españoles que se identifican claramente con el liberalismo político (Prieto menciona a Juan Manuel Quintana, Nicasio Álvarez Cienfuegos y Juan Bautista Arriaza) y penetran entre algunos hombres de letras las ideas de historiadores y preceptistas como el abate Juan Andrés, Juan Francisco Masdeu o Boileau, la difusión de esas ideas no fue generalizada, sino que solo fue oída por una minoría joven e inexperta. Prieto sugiere que la escasa intelectualidad de los mexicanos que vivieron la revolución no estaba preparada para asimilar con rigor y profundidad los nuevos cambios propuestos y esos "hombres ilustrados", dedicados casi exclusivamente a la política, convirtieron el periodismo en un órgano de combate político, un error que la crítica en las décadas precedentes ya denunció, como ha estudiado Mora (1998, p.152).

Volviendo a la producción literaria, reconoce la labor de varias publicaciones periódicas concretas del momento: El Observador de la República Mexicana (1827-1830) y Minerva. 
Periódico literario (1826), y varios poetas y escritores. Sobresalen entre ellos Francisco Manuel Sánchez de Tagle y el poeta cubano José María Heredia; le siguen Francisco Ortega, autor de "Tampico. Cantata heroica", José María Lacunza y Fernando Calderón. Años más tarde, en La Oposición (1834-1835), cuyos redactores fueron Francisco Modesto de Olaguíbel ("noble mecenas de la juventud estudiosa", 1844, p.360), José Joaquín Pesado y Francisco Ortega, publicaron otros tres poetas admirados por Guillermo Prieto: José Bernardo Couto, Pesado y, sobre todo, Manuel Carpio; los dos últimos formarían parte de la Academia de Letrán.

El codirector de El Museo Mexicano se hace eco en esta última parte de "Algunos desordenados apuntes" de la preocupación por el uso correcto de la lengua y la elocución, asunto fundamental para la crítica literaria de esas décadas (Mora, 1998, 2005). Así, subraya la importancia de Andrés Quintana Roo como defensor de la aplicación de las normas de la prosodia y difusor en ese mismo sentido de las ideas de Mariano José Sicilia. En consecuencia, alaba la poesía de Francisco Tagle, comparable a la de los españoles Fernando de Herrera, Fray Luis de León, Leonardo de Argensola o Francisco de Rioja, pero no se olvida de sus "defectos de prosodia insoportables" (1844, p.357). Como señala Mora:

la recién independizada nación provocó que los escritores se enfrentaran a un país que, aunque asumía tácitamente la lengua española como propia, reconocía claramente la ausencia de una tradición (puesto que la literatura, antes de la independencia, era considerada por todos una imitación de la española) y los riesgos de fundar una literatura formalmente descuidada. (2005, p.357)

La publicación en La Oposición de algunas poesías de Francisco Martínez de la Rosa y de su Poética (1827) se convierte para este escritor en un punto de inflexión. En su intento por dar legitimidad a la literatura mexicana dentro de la literatura universal, el autor de los "apuntes" da prioridad a los aspectos formales y también al clasicismo teniendo en cuenta las preceptivas dominantes en España. Se ha visto como Prieto menciona la Poética de Luzán. En la crítica literaria de las décadas precedentes, se tomarán como modelos otros textos de escritores españoles como Alberto Lista, Mariano José Sicilia y José Joaquín de Mora (Mora, 1998). Prieto insiste en este artículo en los "crasos defectos" de prosodia cometidos por poetas como Tagle, Heredia, Carpio y Pesado que combatió Quintana de Roo. La llegada de la Poética de Francisco de la Rosa a México "produjo una verdadera revolución en el buen gusto [...] Existió un código, se uniformaron las opiniones; desaparecieron hasta los últimos restos del gongorismo, y se comenzó a vislumbrar una nueva existencia para las musas mexicanas" (1844, p.360). Para Leonardo Martínez Carrizales, Prieto pretende insertar las letras mexicanas "en el proceso histórico de organización de la teoría literaria de Occidente con base en el sistema retórico orientado a la investigación verbal, preferentemente elocutiva" (2007, p.332). La Poética de Martínez de la Rosa ofrece a las letras mexicanas una preceptiva antidogmática y moderada, muy próxima a las preceptivas clasicistas anteriores y alejada del movimiento romántico (Cebrián, 1990, p.150).

En esa situación se encuentra en el presente la literatura mexicana. Según Guillermo Prieto tiene un modelo preceptivo, el de Martínez de la Rosa, y desde 1836 un grupo de hombres de letras capaces de sentar "la base de una "futura nacionalidad" (1844, p.360): los miembros de la Academia de Letrán. El polígrafo traza muy rápidamente la historia de esta asociación literaria: menciona a sus miembros, alude a algunas de sus vicisitudes y deja para otros la tarea de "designar las fuentes vírgenes de las que se puede sacar la literatura nacional" (p.360), aunque 
insiste en que es en el seno de esa juventud estudiosa donde se haya su futuro. De esta forma se conjugan en el pensamiento de Prieto, como en el de otros escritores y publicistas del momento, los postulados que se apoyan en el aprendizaje de las normas prosódicas y del neoclasicismo con la defensa del principio romántico de la literatura nacional. En ese mismo año, también José María Lafragua había propuesto el año 1836 como hito de la literatura mexicana por los mismos motivos: "Pero a mediados de 1836 unos cuantos jóvenes, que en este momento me oyen, concibieron la idea de reunirse a leer composiciones poéticas en el colegio de San Juan de Letrán. Allí nació la Academia [...]. Tal fue el principio de la literatura actual” (Lafragua, 1996, p.75).

Serán sus miembros los que publicarán en las páginas de El Museo Mexicano: allí editará José María Lacunza los discursos dictados en la Cátedra de historia de la Academia de Letrán; allí verán la luz algunas de sus narraciones, relatos de viajes, artículos costumbristas y un sinfín de traducciones de Manuel Payno y Guillermo Prieto; también, una colaboración de José María Lafragua. En sus páginas se publicará "El poeta en el mundo. A mi amigo D. Fernando Calderón" de Ignacio Rodríguez Galván (1844) y la reseña al volumen de poesías de Calderón (LL.RR., 1844). Otros poetas miembros de la Academia editaron sus creaciones en El Museo: Casimiro Collado, Ramón I. Alcaraz, Juan Navarro, José María Esteva, Alejandro Arango y firma varias colaboraciones Agustín A. Franco, todos ellos citados por Guillermo Prieto en "Algunos desordenados apuntes". La revista defenderá desde sus páginas la producción nacional original que poco a poco se desprenda de las dependencias extranjeras, capaz, como reclamaba Prieto en el artículo, de aclimatarse y convertirse en la literatura característica del pueblo mexicano. Esa importancia en la originalidad de las nuevas letras del país se advierte, por poner un solo ejemplo, en la reseña que los redactores de El Museo escriben sobre las poesías de Fernando Calderón, que se anunciaba en las páginas finales del artículo de Prieto. Los autores destacan de entre sus creaciones las poesías patrióticas del joven poeta, en las que "desaparecen las imitaciones de Arriaza y Cienfuegos: adquiere originalidad, valentía, y dicción e imágenes, todo concurre y obedece a inspiraciones felices" (LL.RR., 1844, p.443).

\section{La literatura española coetánea en El Museo Mexicano}

Junto a las creaciones de estos jóvenes escritores mexicanos, también la literatura española contemporánea tiene cabida en las páginas del semanario. Aunque su presencia es minoritaria, resulta significativo mostrar cómo los nombres de escritores españoles de la literatura del momento que más se repiten son igualmente aquellos que se habían convertido en "modelos" a seguir. Pablo Mora señala a Bretón de los Herreros, Alberto Lista y García Gutiérrez (1998, n. 15, p.155). En “¡A escribir!” el desconocido autor que firma con el seudónimo de Tristán menciona a algunos célebres escritores españoles: en teatro, a Bretón de los Herreros, Zorrilla, García Gutiérrez y Rodríguez Rubí; en poesía, los Cantos del trovador de Zorrilla y los Ensayos poéticos de Salvador Bermúdez de Castro; en las costumbres a Fígaro y a Mesonero (Tristán, 1844 , p. 109). En la reseña a las poesías de Manuel Díaz Mirón que firman los redactores de $E l$ Museo se alaba la belleza de alguna de sus poesías añadiendo que "no desdeñaría Pastor Díaz o Larrañaga de ponerles su nombre al pie.” (RR. del Museo, 1844, p.271).

La publicación reproduce en sus páginas varias composiciones de poetas españoles, siempre contemporáneos; entre ellos, como era de esperar, Alberto Lista, Antonio García Gutiérrez y José Zorrilla; algunos, curiosamente, recogidos en volúmenes publicados fuera de 
España. Así ocurre, por ejemplo, con "A las flores" de Alberto Lista (1843), tomado por los editores de la revista mexicana La colmena. Periódico trimestre de ciencias, artes, historia y literatura, publicado por Ackermann en $1842 .{ }^{4}$ El volumen II de El Museo recoge fragmentos de "A la muerte de una gran señora, de celebrada hermosura" de Serafín Calderón (Calderón, 1844), así firmaba entonces el autor de Cristianos y moriscos. Se trata de una oda que escribió el costumbrista andaluz a la mujer del duque de Frías titulada "Soledad. A la muerte de una señora de celebrada hermosura". El texto es reproducción del que recogió Eugenio de Ochoa en los Apuntes para una biblioteca de escritores españoles (Ochoa, 1840, pp.237-224). ${ }^{5}$

José Zorrilla ocupa un lugar destacado en la revista. Manuel Payno recuerda la dificultad de adquirir libros publicados en España y presenta a los lectores de El Museo Mexicano en el volumen III un resumen de la leyenda "Margarita la tornera" extractado de los Cantos del trovador. Colección de leyendas y tradiciones históricas, publicado en 1841 en la madrileña imprenta de Ignacio Boix:

Como apenas han llegado a esta ciudad unos cuantos ejemplares de esta obra [los Cantos del trovador], suponemos fundadamente que la mayor parte de nuestros amables suscriptores no la conocen, principalmente los de lejanos Departamentos que no tienen la oportunidad de adquirir estos libros. Así pues, y a causa de no tener ningún cuento original con que divertirlos, vamos a darles una ligera idea de esta preciosa leyenda, género en el cual, pocos o acaso ninguno de los modernos poetas españoles, excede a D. José Zorrilla. (M.P., 1844, p.462)

Otro dramaturgo, Ángel de Saavedra, es el protagonista del soneto de Juan Nicasio Gallego "A don Ángel de Saavedra", que apareció en el siguiente volumen de la revista (Gallego,1844, p.94), y que los editores del artículo pudieron extraer de la biografía al Duque de Rivas de la Galería de españoles célebres contemporáneos (Pastor Díaz, 1842, pp.33-34).

También Antonio García Gutiérrez tiene una presencia notable entre los autores españoles. De él se reproduce la "Oración del poeta Jeremías" (1843), tomada de Luz y tinieblas. Poesías sagradas y profanas, publicada un año antes por Ignacio Boix (1842, p.101). Este volumen será el asunto de la "Revisión" que verá la luz en el número siguiente de la revista. Se trata de una extensa reseña del poemario en el que se editan tres composiciones del autor como representantes de los apartados del libro: de los "Romances históricos", "El conde de Saldaña"; de las poesías religiosas, "A la virgen María", aunque al decir de los autores en estas composiciones García Gutiérrez no es poeta romántico; y, de "Poesías profanas", "La luna". En este apartado los redactores se lamentan de que no haya ninguna amorosa. El juicio crítico es taxativo:

En general, nos parece que el Sr. García Gutiérrez, tiene más ingenio, más entusiasmo y más delicadeza para las composiciones dramáticas, que para las líricas. Las poesías en lo general son correctas; pero les falta o el dulcísimo tinte de melancolía de Bermudes [sic]

\footnotetext{
${ }^{4} \mathrm{El}$ texto reproducido en La Colmena y un año después de El Museo es un fragmento de la composición XX titulada "La Vegetación" de las "Poesías profanas" del volumen Poesías (1822: 98-99) y de la edición ampliada de 1834 (123-125).

${ }^{5}$ Curiosamente, los editores seleccionan de entre las poesías que recoge Ochoa, la que menos rasgos hispánicos contiene la antología de textos, frente a "La niña en feria" o un fragmento de "Pulpete y Balbeja".
} 
de Castro, o el entusiasmo y valentía que se nota por ejemplo en algunas piezas de Pastor Díaz. (Los RR., 1844, p.511)

No obstante, según los autores de la reseña, solo Zorrilla le excede en calidad, pues "no tiene rival entre los poetas modernos, en este género de composiciones" (Los RR., 1844, p.512). Parece, además, que los redactores de la revista tuvieron en cuenta para la selección de los textos españoles aspectos relacionados con la actualidad de la vida cultural del país. Así, en el teatro principal de México se representó durante el verano de 1843 Zaida del autor de El trovador, según un breve comentario en la sección de "Teatros" de la revista (Anónimo, 1843, p.264), circunstancia que puede explicar que El Museo recurra a textos poéticos o prosísticos de los dramaturgos cuyas obras podían los lectores haber visto en escena. La misma razón puede explicar que la publicación entre 1842 y 1843 en México de los seis volúmenes del Teatro de Bretón de los Herreros, fuera el acicate para que El Museo Mexicano reprodujese el artículo de costumbres del comediógrafo titulado "La nodriza" (Bretón de los Herreros, 1844), que había aparecido en 1843 en el volumen madrileño de Los españoles pintados por sí mismos y que contribuiría a difundir la obra del escritor riojano como modelo literario (Bretón de los Herreros, 1843). La novela española se representa también con "El pasaporte falso (Novela)" de Juan Martínez Villergas (1845), que se había publicado en El Dómine Lucas (Martínez Villergas, 1844).

En cualquier caso, los poetas, prosistas y dramaturgos cuyas obras se ven reproducidas en el semanario son representantes del romanticismo español moderado y ecléctico. Nada hay de Espronceda, ni de García de Tassara en poesía; nada del Don Álvaro del primer Duque de Rivas. En esa misma línea de política cultural debe situarse la relación entablada entre Museo Mexicano (ahora sin el artículo pues como se recordará cambia mínimamente su título en su Segunda época) durante enero de 1845 y marzo de 1846 con la revista madrileña, representante también del romanticismo moderado español, El Laberinto (1843-1845). Esta publicación tuvo como directores al escritor costumbrista Antonio Flores desde noviembre de 1843 a marzo de 1845 y a Antonio Ferrer del Río desde mayo a octubre de 1845. En ella colaboró asiduamente Juan Eugenio Hartzenbusch.

El mediador entre El Laberinto y El Museo Mexicano pudo ser este último o Antonio Ferrer del Río. El primero había sido admitido como socio del Ateneo Mexicano, según una carta firmada por Guillermo Prieto del 2 de mayo de 1844 dirigida al bibliófilo español, que se encuentra entre los "Papeles" del escritor depositados en la Biblioteca Nacional de España. Antonio Ferrer del Río había viajado a Cuba y México como comisionado del editor Ignacio Boix unos años antes para establecer dos sucursales de su empresa (Peñas, 2018, p.142). Si confiamos en la memoria de José Zorrilla, que refiere este dato en sus Recuerdos del tiempo viejo (1879), Ferrer del Río volvió a España en 1842, pero durante su estancia en México pudo conocer a Ignacio Cumplido, que entonces editaba El Mosaico Mexicano (1836-1842). Repárese en que parte de los textos reseñados o reproducidos en el semanario de México que se han mencionado anteriormente son ediciones de Boix.

El trasvase de textos de El Laberinto a Museo Mexicano comienza en el número 3 de enero de 1845, al iniciarse la Segunda época, cuando la revista mexicana reproduce "Trozos del retrato histórico de don Enrique de Aragón, Marqués de Villena. Obra premiada por el Liceo de Madrid en los juegos florales de 1843" (Hartzenbusch, 1845). El ensayo se había publicado en los números 9 y 10 de marzo de 1844 de la revista madrileña (Hartzenbusch, 1843). A continuación, en números sucesivos se editan otros textos procedentes de la misma publicación 
española como "Recuerdos de un viaje a la isla de Cuba" de Antonio Ferrer del Río (F. del Río, 1845a), que había publicado El Laberinto el número del 1 de junio de 1844, junto con alguno de los grabados que acompañaban a la primera edición del texto (F. del Río, 1844b). Del mismo polígrafo español se reproducen dos de las biografías del autor en la revista española, acompañadas de las litografías: la de Béranger (F. del Río, 1844c, 1845c) y la Vasco Núñez de Balboa (F. del Río, 1844a y 1845b). Le sigue "Frenología aplicada a la economía doméstica" de Antonio Flores (1845) que se había publicado el 1 de julio de 1844 en la revista española (Flores, 1843). Finalmente, también se edita el artículo que Hartzenbusch dedicó a la leyenda de Los amantes de Teruel, que apareció sin firma en Museo Mexicano (Anónimo, 1845, pp.558-564). El texto coincide, salvo la elisión del primer párrafo, con el de El Laberinto, publicado el 16 de diciembre de 1843 (Hartzenbusch, 1843) y reproduce también el grabado de las momias de los amantes encontradas en Teruel.

\section{Conclusiones}

Como publicación "clave para entender la formación de las letras nacionales en el XIX" (Mora, en Ruedas de la Serna, 1996, p.111), El Museo Mexicano se hace eco de las reflexiones de los miembros del Ateneo mexicano a propósito de la literatura nacional y, en especial, de la Academia de Letrán. Uno de ellos, Guillermo Prieto, codirector junto a Manuel Payno durante la Primera época de la revista, publica en sus páginas un artículo en el que pone de manifiesto de qué modo la incipiente creación de una historia de la literatura mexicana parte del análisis de la producción literaria propia en comparación con la literatura española, para mostrar hasta qué punto la política colonial cercena las aspiraciones de una verdadera literatura nacional, tomando en cuenta por este último concepto la intrínseca relación entre literatura y sociedad y el papel del poeta como mediador. El autor coincide con otros polígrafos del momento en las reflexiones en torno a la literatura prehispánica, ahogada durante la conquista, y la expresión literaria nacional nacida de la independencia, contaminada por la actividad política. A diferencia de otros textos de la época, Prieto realiza un diagnóstico de la literatura de los siglos XVI, XVII y XVIII en comparación con la literatura española para determinar su total dependencia de la primera respecto de la colonizadora y llamar la atención, como la crítica literaria de la época, sobre la importancia en la corrección en los aspectos formales y la necesidad de seguir las preceptivas clasicistas dominantes. Tras el periodo convulso de la independencia y en el momento en que se escribe el artículo, Guillermo Prieto cree llegadas las circunstancias propicias para la producción de una verdadera literatura nacional gracias a la presencia en México de un modelo retórico idóneo para la literatura nacional, la Poética de Francisco Martínez de la Rosa, y la producción literaria de los jóvenes miembros de la Academia de Letrán. En este sentido, "Algunos desordenados apuntes" se distingue por su afán por conjugar el esfuerzo de síntesis en relación con la periodización de la literatura nacional y sus aportaciones relativas al canon dirigido a organizar el sistema literario mexicano, con las reflexiones de carácter propedéutico que difundía la política cultural del momento.

Aun tratándose de una de las revistas en las que publican sobre todo autores nacionales, $E l$ Museo Mexicano no olvida los modelos españoles y europeos, que, en menor medida, se presentan en sus páginas. De entre los autores españoles, siempre contemporáneos, de los que ven la luz especialmente poesías, algunos textos costumbristas y artículos de carácter literario, 
sobresalen aquellos escritores propuestos como modelos por cultivar un romanticismo ecléctico, mesurado, alejado de las "exageraciones" románticas: las poesías de Alberto Lista, José Zorrilla, Antonio García Gutiérrez se reproducen en sus páginas junto a uno de los textos costumbristas más conocidos de Manuel Bretón de los Herreros. En este mismo sentido, el trasvase de textos de la revista romántica El Laberinto a la revista mexicana durante su Segunda época pone de manifiesto la defensa de un proyecto cultural semejante que comparten las dos publicaciones periódicas, pues ambas deben enmarcarse en el proceso de construcción de sus respectivas literaturas nacionales observado desde un prisma moderado.

\section{Referencias bibliográficas}

A. L. [Alberto Lista]. (1843). A las flores. El Museo Mexicano, I, 299.

Alcalá Galiano, A. (1843). Juicio crítico sobre nuestros poetas más célebres de fines del siglo XVIII: Meléndez Valdés. El Laberinto, 3 (1 de diciembre), 29-31. . (1845). Meléndez Valdés. Juicio crítico de sus obras. Museo Mexicano, I, 289-294.

Alonso Sánchez, M. (2001). Una empresa educativa y cultural de Ignacio Cumplido: El Museo Mexicano (1843-1846). En L. Suárez de la Torre, y M.A. Castro (ed.), Empresa y cultura en tinta y papel (1800-1860) (pp. 553-560). México: Instituto de Investigaciones Dr. José María Luis MorUNAM.

Anónimo. (1843). Teatros. El Museo Mexicano, II, 264). . (1844). ¡A escribir! El Museo Mexicano, IV, 108-110. . (1845). Los Amantes de Teruel. Museo Mexicano, I, 558-564.

Bretón de los Herreros, M. (1842-1843). Teatro. México: Vicente García Torres, 1842-1843, 6 vols. . (1843). La nodriza. En Los españoles pintados por sí mismos (I, 104-112). Madrid: Ignacio

Boix. Recuperado de http://bdh.bne.es/bnesearch/detalle/bdh0000016568 . (1844). La nodriza. El Museo Mexicano, IV, 302-304.

Calderón, S. [Estébanez Calderón, Serafín]. (1844). A la muerte de una señora, de celebrada hermosura (Fragmentos). El Museo Mexicano, II, 467-468.

Castro, M.A., y Curiel, G. (2000). Publicaciones periódicas mexicanas del siglo XIX: 1822-1855.

México: Universidad Autónoma de México.

Cebrián, J. (1990). Significación y alcance de la Poética de Martínez de la Rosa. Revista de Literatura, 52 (103), 129-150.

Díaz Arciniega, V. (1996). Luis de la Rosa. En J.A. Ruedas de la Serna (Coord.), La misión del escritor: ensayos mexicanos del siglo XIX (pp.79-85). México: UNAM.

F. del Río, A. (1844a). Personajes ilustres en la conquista de América. Descubrimiento del Mar del Sur. Vasco Núñez de Balboa. El Laberinto, I, 5 (1 de enero), 57-59. . (1844b). Recuerdos de un viaje a la isla de Cuba. El Laberinto, I, 13 (1 de junio), 203-205. . (1844c). Biografía. Béranger. El Laberinto, I (17) (1 de julio), 225-227. . (1845a). Recuerdos de un viaje a la isla de Cuba. Museo Mexicano, I, 224-228. 
. (1845b). Vasco Núñez de Balboa. Museo Mexicano, I, 259-265.

. (1845c). Béranger. Museo Mexicano, I, 311-315.

Flores, A. (1844). Frenología aplicada a la economía doméstica. El Laberinto, I, 17 (1 de julio), 233-235. . (1845). Frenología aplicada a la economía doméstica. El Museo Mexicano, I, 512-516.

GG. PP. (1844). Algunos desordenados apuntes que pueden considerarse cuando se escriba la historia de la bella literatura mexicana. El Museo Mexicano, IV, 354-360.

Gallego, J.N. (1844). A don Ángel de Saavedra. El Museo Mexicano, IV, 94.

García Gutiérrez, A. (1842). Luz y tinieblas. Poesías sagradas y profanas. Madrid: Boix Editor. . (1843). Oración del poeta Jeremías. El Museo Mexicano, I, 517.

G.P. [Guillermo Prieto] (1844). Algunos desordenados apuntes que pueden considerarse cuando se escriba la historia de la bella literatura mexicana. El Museo Mexicano, IV, 534-360.

Guerra, F.-X. (1992). Modernidad e independencias. Ensayos sobre las revoluciones hispánicas. Madrid: Fundación Mapfre América.

Hartzenbusch, J.E. (1843). Los amantes de Teruel. El Laberinto, I (4) (16 de diciembre), pp.46-48. . (1844). Trozos del retrato histórico de don Enrique de Aragón, Marqués de Villena. Obra premiada por el Liceo de Madrid en los juegos florales de 1843. El Laberinto, I, .9 (1 de marzo), 114-115; 10 (16 de marzo), 131-132.

. (1845). Trozos del retrato histórico de don Enrique de Aragón, Marqués de Villena. Obra premiada por el Liceo de Madrid en los juegos florales de 1842. Museo Mexicano, I, 51-57.

Lacunza, J. Ma . (1844). Literatura mexicana. Discurso pronunciado por el Sr. Lic. Don José María Lacunza en la apertura de la Cátedra de Humanidades del Colegio de San Juan de Letrán. El Museo Mexicano, II, 363-368.

Lafragua, J. Mª (1996). Carácter y objeto de la literatura. En J. Ruedas de la Serna, (Coord..), La misión del escritor. Ensayos mexicanos del siglo XIX (pp.69-77). México: UNAM.

Lista, A. (1822). Poesías. Madrid: Imprenta de don León Amarita. . (1834). Poesías. Paris: Librería de los SS. de D. Vicente Salvá é Hijo.

LL.RR. (1844). Bibliografía. Parnaso mexicano. - Obras poéticas de D. Fernando Calderón. El Museo Mexicano, IV, 442-442.

. (1843). A las flores. El Museo Mexicano, I, 299.

Los RR. (1844). Poesía española. Revisión de obras. Luz y tinieblas de D. Antonio García Gutiérrez. El Museo Mexicano, III, 509-512.

M.P. (1843). Revisión de obras. Cantos populares del norte, traducidos al francés por X. Marmier. El Museo Mexicano, II, 202-204.

. (1844). Literatura española. Los cantos del trovador por D. José Zorrilla. Margarita la tornera. El Museo Mexicano, III, 462-466.

Martínez, J. L. (1951). Historiografía de la literatura mexicana: desde los orígenes hasta Francisco Pineda. Nueva Revista de Filología Hispánica, 5 (1), 38-68.

Martínez Carrizales, L. (2007). La organización teórica del sistema literario en el México del siglo XIX. En Ma del Carmen García Tejera, I. Morales Sánchez, F. Coca Ramírez y J.A. Hernández Guerrero (Eds.). Lecturas del pensamiento filosófico, estético y político. XIII Encuentro de la Ilustración al Romanticismo. 1750-1850. Cádiz, América y Europa ante la Modernidad (321336). Cádiz: UCA.

Martínez Villergas, J. (1844). El pasaporte falso (Novela). El Dómine Lucas, Enciclopedia pintoresca universal, 3 (1 de junio), 22-23.

. (1845). El pasaporte falso (Novela). Museo Mexicano, I, 544-548 
Mora, P. (1996). Guillermo Prieto. En J. Ruedas de la Serna La misión del escritor: ensayos mexicanos del siglo XIX (pp. 103-109). México: UNAM. (1998). Orígenes de la crítica literaria en México. En J. Ruedas de la Serna (Coord.), De la perfecta expresión: preceptistas iberoamericanos. Siglo XIX (pp.150-165) México: UNAM. . (2005). La crítica literaria en México: 1826-1860. En B. Clark de Lara y E. Speckman Guerra (Eds.), La República de las Letras. Asomos de una cultura escrita del México decimonónico. Vol. I. Ambientes, asociaciones y grupos. Movimientos, temas y géneros literarios (pp.355-376). México: UNAM.

Ochoa, E. de O. (1840). Apuntes para una biblioteca de escritores españoles. Paris: Baudry Librería Europea. Recuperado de http://www.cervantesvirtual.com/obra/apuntes-para-una-biblioteca-deescritores-espanoles-contemporaneos-en-prosa-y-verso-tomo-segundo--0/

Pastor Díaz, N. (1842). D. Ángel de Saavedra, Duque de Rivas. En N. Pastor Díaz y F. de Cárdenas. Galería de españoles célebres contemporáneos, ó Biografías y retratos de todos los personajes de nuestros días en las ciencias, en la política, en las armas, en las letras y en las artes (I, pp.164). Madrid: Imprenta de don Vicente de Lalana. Recuperado de https://academia.gal/monografias/paxinas.do?id=73

Peñas Ruiz, A. (2018). Un "editor infatigable": la trayectoria biográfica, editorial y empresarial de Ignacio Boix. Cuadernos de Ilustración y Romanticismo, 24, 133-151.

Pérez, A. C. (2005). El pasado como objeto de colección y la historia como ciencia moral. Una aproximación historiográfica a la revista El Museo Mexicano. TZINTZUN. Revista de Estudios Históricos, 41 (enero-junio), 35-56.

Pérez Vejo, T. (2010). La difícil herencia: hispanofobia e hispanofilia en el proceso de construcción nacional mexicano. En M. Suárez Cortina y T. Pérez Vejo (Eds.), Los caminos de la ciudadanía. México y España en perspectiva comparada (pp.219-229). Madrid: Editorial Biblioteca Nueva.

Rodríguez Galván, I. (1844). El poeta en el mundo. A mi amigo D. Fernando Calderón. El Museo Mexicano, IV, 192.

Rosa, L. de la. (1996). Utilidad de la literatura en México. En J. Ruedas de la Serna (Coord.), La misión del escritor: ensayos mexicanos del siglo XIX (pp.87-101). México: UNAM.

RR. del Museo (1844). Literatura contemporánea. El Veracruzano. - El Pobre Peregrino. El Museo Mexicano, III, 171-172.

Ruedas de la Serna, J. (Coord.) (1996). En J. Ruedas de la Serna (Coord.), La misión del escritor: ensayos mexicanos del siglo XIX. México: UNAM

Ruiz Castañeda, M ${ }^{\mathrm{a}}$ del C. (2014). José Justo Gómez de la Cortina, conde de la Cortina (1799-1860). En J. Ruedas de la Serna, (Coord.), La misión del escritor. Ensayos mexicanos del siglo XIX (pp.4760). México: UNAM.

Suárez Cortina, M. y T. Pérez Vejo (2010). Convergencias y divergencias. La pertinencia de una comparación. En M. Suárez de la Cortina y T. Pérez Vejo (Eds.), Los caminos de la ciudadanía. México y España en perspectiva comparada (pp.9-34). Madrid: Editorial Biblioteca Nueva.

Tola de Habich, F. (2005). Propuesta para una periodización generacional de la literatura mexicana del siglo XIX. En B. Clark de Lara y E. Speckman Guerra (Eds.), La República de las Letras. Asomos de una cultura escrita del México decimonónico. Vol. I. Ambientes, asociaciones y grupos. Movimientos, temas y géneros literarios (pp.203-220). México: UNAM.

Treviño García, B.E. (1996). Justo Gómez de la Cortina. Conde de la Cortina. En J. Ruedas de la Serna, (Coord.), La misión del escritor. Ensayos mexicanos del siglo XIX (pp.61-67). México: UNAM.

Tristán. (1844). ¡A escribir! El Museo Mexicano, IV, 108-110. 
Vega y Ortega Báez, R. A. (2014). La colección territorial sobre la República Mexicana de El Museo Mexicano (1843-1846). Revista de El Colegio de San Luis, IV (7/ (julio-diciembre), 98-127. Recuperado de https://www.academia.edu/19793212/La_colecci\%C3\%B3n_territorial_sobre_la_Rep\%C3\%BAb lica_Mexicana_de_El_Museo_Mexicano_1843-1846_ 